\title{
AVALIAÇÃO DE PROGRAMAS NUTRICIONAIS COM A UTILIZAÇÃO DE CARBOIDRASES E FITASE EM RAÇÕES DE FRANGOS DE CORTE
}

\author{
Bruno Duarte Alves Fortes ${ }^{1}$, MARCos BARCELlos CAFE ${ }^{2}$, Jose Henrique Stringhini ${ }^{2}$,

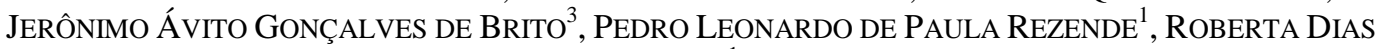 \\ SILVA ${ }^{1}$ \\ ${ }^{1}$ Pós-graduando em Ciência Animal da Escola de Veterinária e Zootecnia da Universidade Federal de Goiás, Goiânia, GO, Brasil - \\ fortesbruno@zootecnista.com.br \\ ${ }^{2}$ Professores Doutores da Escola de Veterinária e Zootecnia da Universidade Federal de Goiás, Goiânia, GO, Brasil \\ ${ }^{3}$ Professor Doutor do Centro de Ciências Agrárias, Ambientais e Biológicas - Universidade Federal do Recôncavo da Bahia, Cruz \\ das Almas - BA, Brasil
}

O experimento foi conduzido para avaliar programas nutricionais associados à suplementação de enzimas (carboidrases e fitase) em rações de frangos de corte sobre o desempenho e características de carcaça. Foram utilizados 2016 pintos de corte machos de um dia da linhagem Cobb-500, distribuídos em 32 boxes e alimentados com rações à base de milho e farelo de soja. Utilizou-se delineamento experimental inteiramente casualizado, com quatro tratamentos e oito repetições com 63 aves por parcela. Os tratamentos utilizados foram: T1 programa nutricional Cobb; T2 - redução de $4 \%$ na energia metabolizável aparente (EMA); de 3\% proteína bruta $(\mathrm{PB})$ e de $10 \%$ nas recomendações dos aminoácidos do T1; T3 - dieta reformulada isonutriente a T1 com 200 $\mathrm{g} / \mathrm{t}$ carboidrases $+50 \mathrm{~g} / \mathrm{t}$ fitase; T4 - dieta reformulada isonutriente a T2 com $200 \mathrm{~g} / \mathrm{t}+50 \mathrm{~g} / \mathrm{t}$ fitase. Não foi observada diferença sobre a conversão alimentar e características de carcaça na fase integral (1-42dias) de criação para os diferentes tratamentos. Contudo, o consumo de ração, peso médio ao abate e o ganho de peso foram afetados significativamente, sendo que os tratamentos suplementados com enzimas apresentaram maior consumo de ração do que os tratamentos sem a suplementação enzimática, maior peso médio ao abate e maior ganho de peso. Conclui-se que o uso das carboidrases associadas à inclusão de fitase foi efetivo para elevar a energia metabolizável aparente das rações à base de milho e farelo de soja. A adição das enzimas na dieta das aves permitiu um aumento no consumo de ração de $5,18 \%$ e melhoria no ganho de peso de $4,39 \%$.

PALAVRAS-CHAVE: aves; carboidrases; desempenho; fitase; rendimento.

\section{EVALUATION OF NUTRITIONAL PROGRAMS ASSOCIATED TO CARBOHYDRASES AND PHYTASE SUPPLEMENTATION TO BROILER DIETS}

\section{ABSTRACT}

This experiment was conducted to evaluate the effect of different nutritional programs associated to enzyme supplementation (carbohydrases and phytase) on performance and carcass characteristics. A total of 2,016 male broiler chicks of Cobb-500 strain were allotted in third-two pens and fed diets based on corn and soybean meal. A completely randomized design with four treatments and eight replicates of 63 birds each was used. The treatments were designed as follows: $\mathrm{T} 1$ - nutritional program recommended for Coob-500; T2 -T1 nutritional program with reduction of $4 \%$ of metabolizable energy (ME), $3 \%$ of crude protein (CP) and $10 \%$ of all amino acids; T3 - T1 nutritional program with $200 \mathrm{~g} / \mathrm{T}$ of carbohydrases and $50 \mathrm{~g} / \mathrm{T}$ of phytase; and $\mathrm{T} 4-\mathrm{T} 2$ nutritional program with $200 \mathrm{~g} / \mathrm{T}$ of carbohydrases and $50 \mathrm{~g} / \mathrm{T}$ of phytase. The results showed no statistical difference in feed conversion ratio and carcass characteristics for all treatments in the period of 1 to 42 days of age. However, feed consumption, slaughter weight and weight gain were affected, the treatments supplemented 
with enzymes had greater feed consumption than the treatments without enzyme supplementation, besides the highest slaughter weight and weight gain. In conclusion, the use of carbohydrases associated with phytase enzymes was effective to increase the apparent metabolizable energy of diets based on corn and soybean meal. The addition of enzymes to the diet of broilers led to an increase in feed consumption of $5.18 \%$, and improved weight gain in $4.39 \%$.

KEYWORDS: broilers; carbohydrases; carcass characteristics; performance; phytase.

\section{INTRODUÇÃO}

Dentre os aditivos alimentares comumente utilizados nas rações avícolas, destacam-se as enzimas exógenas que têm sido incorporadas às dietas dos animais com o intuito de melhorar o desempenho das aves, pois atuam como catalisadores biológicos no metabolismo dos animais.

A disponibilidade dos nutrientes nos alimentos é frequentemente limitada pela presença de fatores antinutricionais. De acordo com THORPE \& BEAL (2001), trata-se de fatores com efeitos depressivos sobre a digestão e a utilização de proteínas; com efeitos negativos sobre a digestão de carboidratos e minerais; fatores que inativam vitaminas ou aumentam sua exigência para o animal; que estimulam o sistema imune e que podem causar danos por reação de hipersensibilidade e fatores com efeito tóxico.

A maioria das dietas de frangos de corte, no Brasil são constituídas de alimentos de origem vegetal, sendo o milho e o farelo de soja a base da alimentação das aves. Contudo, esses alimentos apresentam constituintes que são indigeríveis pelas aves, entre eles, os polissacarídeos não amiláceos (PNAs) e o ácido fítico são de grande importância. O milho contém aproximadamente $8 \%$ de polissacarídeos não amiláceos insolúveis, principalmente arabinoxilanos (CHOCT, 2006). Já o farelo de soja contém cerca de $16 \%$ de polissacarídeos não amiláceos insolúveis (IRISH \& BALNAVE, 1993).

Para OPALINSKI et al. (2010), a presença de polissacarídeos não amiláceos solúveis no lúmen intestinal aumenta a viscosidade da digesta, pois formam polímeros ou géis com a água, que comprometem a digestão e absorção dos nutrientes, por dificultar a ação das enzimas digestivas e a difusão das substâncias relacionadas com a digestão e absorção.

A suplementação enzimática tem promovido melhora no valor nutritivo de dietas à base de milho e farelo de soja para frangos de corte. Segundo ZANELLA et al. (1999) e ONDERCI et al. (2006), a digestibilidade e o desempenho das aves melhoram com a adição de complexos enzimáticos (amilase, protease, xilanase), pois proporcionam maior disponibilidade de aminoácidos e maior aproveitamento da proteína da dieta, refletindo em melhores resultados de desempenho de frangos de corte.

CONTE et al. (2002) avaliaram o uso de carboidrases e fitase sobre a energia metabolizável aparente (EMA) e energia metabolizável aparente corrigida pelo nitrogênio (EMAn) do farelo de arroz integral e verificaram aumento nos valores energéticos quando se utilizaram carboidrases na ração. Já a fitase, utilizada simultaneamente com as carboidrases, não melhorou a energia metabolizável do farelo de arroz integral.

Efeitos positivos da suplementação enzimática em rações de frangos de corte elaboradas com milho e farelo de soja foram verificados sobre a conversão alimentar (GRACIA et al., 2003; ONDERCI et al., 2006; CARVALHO et al., 2009), peso corporal (ODETALLAH et al., 2005; FRANCESCH \& GERAERT, 2009) e ganho de peso (COSTA et al., 2004; CARVALHO et al., 2009).

O presente trabalho foi conduzido para avaliar o efeito da adição de um complexo enzimático associado à fitase em dois padrões nutricionais sobre o desempenho e características de carcaça de frangos de corte de 1 a 42 dias de idade alimentados com rações à base de milho e farelo de soja.

\section{MATERIAL E MÉTODOS}

O experimento foi conduzido no Aviário Experimental da empresa avícola Abatedouro São Salvador/Super Frango em Itaberaí-GO. Foram alojados 2016 pintos de corte, com densidade de 
alojamento de 12 aves $/ \mathrm{m}^{2}$, provenientes de incubatório comercial, com um dia de idade, acondicionados em dois galpões de alvenaria semelhantes, divididos em 16 boxes cada. Cada boxe continha bebedouro pendular e comedouro tubular infantil até o sétimo dia de idade e adulto a partir desse momento.

As aves foram vacinadas contra Doença de Gumboro na data específica $\left(21^{\circ} \mathrm{dia}\right)$, conforme os desafios da região. O programa de luz adotado foi contínuo com 12 horas de iluminação natural e 12 horas de iluminação artificial por dia, durante todo o período experimental. A iluminação artificial foi feita por lâmpadas incandescentes de 100 W espalhadas na cumeeira do galpão, buscando o fornecimento de 22 lúmens $/ \mathrm{m}^{2}$.

Utilizou-se o delineamento experimental inteiramente casualizado (DIC) com quatro tratamentos e oito repetições, em que cada boxe representou uma parcela experimental composta por 63 aves.

Os tratamentos adotados foram os seguintes: $\mathrm{T} 1$ - programa nutricional proposto para linhagem Cobb 500; T2 - programa nutricional Cobb 500, decrescido de $4 \%$ nas exigências das aves de energia metabolizável aparente (EMA), de 3\% de proteína bruta (PB) e de $10 \%$ nas recomendações dos aminoácidos de T1; T3 - dieta isonutricional à T1, com suplementação de complexo enzimático $(200 \mathrm{~g} / \mathrm{t}$ carboidrases + $50 \mathrm{~g} / \mathrm{t}$ fitase), utilizando-se a valorização nutricional preconizada pelo fabricante de 1,5\% para EMA $(\mathrm{kcal} / \mathrm{kg})$ do milho, de $6 \%$ para EMA (kcal $/ \mathrm{kg})$ do farelo de soja, e de $2 \%$ de PB e aminoácidos digestíveis limitantes (Metionina, Metionina + Cistina, Lisina, Treonina e Triptofano); $\mathrm{T} 4$ - dieta isonutricional à $\mathrm{T} 2$, com suplementação de complexo enzimático (200 g/t carboidrases $+50 \mathrm{~g} / \mathrm{t}$ fitase), utilizando-se a valorização nutricional preconizada pelo fabricante de $1,5 \%$ para EMA $(\mathrm{kcal} / \mathrm{kg})$ do milho, de 6\% para EMA $(\mathrm{kcal} / \mathrm{kg})$ do farelo de soja, de $2 \%$ de PB e aminoácidos digestíveis limitantes (Metionina, Metionina + Cistina, Lisina, Treonina e Triptofano).
O complexo enzimático (CE) continha as enzimas $\beta$-glucanase (min. $1.100 \mathrm{U} / \mathrm{g}$ ), xilanase (min. $1.500 \mathrm{U} / \mathrm{g}$ ), $\alpha$-galactosidade (min. $35 \mathrm{U} / \mathrm{g}$ ) e galactomananase (min. $110 \mathrm{U} / \mathrm{g}$ ). A enzima fitase utilizada, de origem bacteriana Escherichia coli, apresenta atividade inicial mínima declarada pelo fabricante de $10.000 \mathrm{ftu} / \mathrm{g}$. A matriz nutricional adotada com o uso da fitase foi $8000 \%$ de proteína bruta (PB), $600.000 \mathrm{kcal} / \mathrm{kg}$ de energia metabolizável aparente (EMA), 3000\% de cálcio e $2400 \%$ de fósforo disponível. Dessa forma, considerou-se que a fitase contribuiu com $30 \mathrm{kcal}$ de EMA, 0,40\% de PB, $0,15 \%$ de cálcio, $0,12 \%$ de fósforo, $0,014 \%$ de metionina + cistina, $0,019 \%$ de lisina e $0,013 \%$ de treonina.

As dietas experimentais (Tabelas 1 e 2 ) foram formuladas à base de milho, farelo de soja e farinha de origem animal de acordo com as recomendações práticas para a linhagem Cobb 500 com base na composição bromatológica dos ingredientes descrita por ROSTAGNO et al. (2005). O manejo geral da criação, incluindo instalação, limpeza de equipamentos e manejo de cortinas, foi o comumente adotado em granjas comerciais.

Durante a condução do experimento procedeu-se à pesagem das aves e das rações no $1^{\circ}$, $7^{\circ}, 21^{\circ}, 35^{\circ}$ e $42^{\circ}$ dia de idade para avaliação do desempenho, por meio do consumo de ração (CR), em gramas, do ganho de peso (GP), em gramas, e da conversão alimentar (CA). Ao término do experimento, duas aves de cada unidade experimental, representantes do peso médio da unidade, foram selecionadas e abatidas após jejum de 6 horas para avaliação de rendimento de carcaça.

Foi medido o peso da ave viva na plataforma do abatedouro, peso da carcaça eviscerada, do peito, das coxas e sobrecoxas e o peso da gordura abdominal, considerada como a quantidade de gordura depositada na região próxima à Bursa de Fabricius, e aquela encontrada aderida à moela e ao pró-ventrículo. Os valores obtidos foram relacionados ao peso vivo e eviscerado das aves, sendo apresentados em percentagem. 
TABELA 1- Composição percentual e níveis nutricionais calculados das rações experimentais nas fases pré-inicial e inicial

\begin{tabular}{|c|c|c|c|c|c|c|c|c|}
\hline \multirow[b]{2}{*}{ Ingredientes } & \multicolumn{4}{|c|}{ Pré-inicial } & \multicolumn{4}{|c|}{ Inicial } \\
\hline & $\mathrm{T} 1$ & $\mathrm{~T} 2$ & T3* & $\mathrm{T} 4 *$ & $\mathrm{~T} 1$ & $\mathrm{~T} 2$ & T3* & T4* \\
\hline Milho & 54,99 & 59,93 & 58,63 & 58,10 & 57,33 & 62,17 & 62,34 & 63,51 \\
\hline Farelo de soja, $45 \%$ & 33,09 & 30,56 & 32,51 & 31,00 & 30,19 & 27,77 & 29,42 & 27,68 \\
\hline Far. Carne e osso, $40 \%$ & 7,20 & 7,21 & 5,24 & 5,29 & 6,45 & 6,46 & 4,47 & 4,51 \\
\hline Gordura de aves & 2,57 & 0,38 & 0,50 & 0,20 & 3,75 & 1,53 & 1,23 & 0,28 \\
\hline Calcário & 0,10 & 0,11 & 0,33 & 0,32 & 0,36 & 0,37 & 0,58 & 0,58 \\
\hline Sal comum & 0,38 & 0,38 & 0,41 & 0,42 & 0,34 & 0,34 & 0,38 & 0,38 \\
\hline Suplemento vitamínico ${ }^{1}$ & 0,05 & 0,05 & 0,05 & 0,05 & 0,05 & 0,05 & 0,05 & 0,05 \\
\hline Suplemento mineral $^{2}$ & 0,06 & 0,06 & 0,06 & 0,06 & 0,06 & 0,06 & 0,06 & 0,06 \\
\hline Dl-metionina (99\%) & 0,296 & 0,216 & 0,282 & 0,209 & 0,266 & 0,195 & 0,252 & 0,184 \\
\hline L-lisina $(78 \%)$ & 0,268 & 0,173 & 0,268 & 0,154 & 0,232 & 0,147 & 0,236 & 0,139 \\
\hline L-treonina $(99 \%)$ & 0,109 & 0,047 & 0,099 & 0,035 & 0,082 & 0,026 & 0,072 & 0,015 \\
\hline Promotor de crescimento ${ }^{3}$ & 0,620 & 0,620 & 0,620 & 0,620 & 0,395 & 0,395 & 0,395 & 0,395 \\
\hline Anticoccidiano $^{4}$ & 0,270 & 0,270 & 0,270 & 0,270 & 0,495 & 0,495 & 0,495 & 0,495 \\
\hline Complexo enzimático & - & - & 0,020 & 0,020 & - & - & 0,020 & 0,020 \\
\hline Fitase & - & - & 0,005 & 0,005 & - & - & 0,005 & 0,005 \\
\hline Caulin & - & - & 0,71 & 3,25 & - & - & - & 1,70 \\
\hline Total & 100,00 & 100,00 & 100,00 & 100,00 & 100,00 & 100,00 & 100,00 & 100,00 \\
\hline \multicolumn{9}{|c|}{ Composição nutricional calculada } \\
\hline 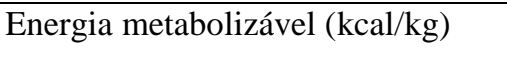 & 2980 & 2891 & 2980 & 2891 & 3080 & 2988 & 3080 & 2988 \\
\hline Proteína bruta (\%) & 23,00 & 22,08 & 23,00 & 22,08 & 21,50 & 20,64 & 21,50 & 20,64 \\
\hline Lisina digestível (\%) & 1,28 & 1,15 & 1,28 & 1,15 & 1,17 & 1,05 & 1,17 & 1,05 \\
\hline Metionina + Cistina digestível (\%) & 0,90 & 0,81 & 0,90 & 0,81 & 0,84 & 0,76 & 0,84 & 0,76 \\
\hline Treonina digestível (\%) & 0,83 & 0,75 & 0,83 & 0,75 & 0,76 & 0,69 & 0,76 & 0,69 \\
\hline Cálcio (\%) & 1,00 & 1,00 & 1,00 & 1,00 & 1,00 & 1,00 & 1,00 & 1,00 \\
\hline Fósforo disponível (\%) & 0,55 & 0,55 & 0,55 & 0,55 & 0,50 & 0,50 & 0,50 & 0,50 \\
\hline Sódio & 0,22 & 0,22 & 0,22 & 0,22 & 0,20 & 0,20 & 0,20 & 0,20 \\
\hline
\end{tabular}

${ }^{\mathrm{T}}$ Enriquecimento de vitaminas por kg de ração: selênio $0,30 \mathrm{mg}$; vitamina A $10.000 \mathrm{UI}$; vitamina D3 $2.500 \mathrm{UI}$; vitamina E $25 \mathrm{mg}$; vitamina K3 $2 \mathrm{mg}$; vitamina B1 2,50 mg; vitamina B2 6,50 mg; vitamina B6 3,50 mg; vitamina B12 18 mcg; ácido fólico 1,20 mg; ácido pantotênico $15 \mathrm{mg}$; niacina $42 \mathrm{mg}$; biotina $80 \mathrm{mcg}$; etoxiquin $166 \mathrm{mg}$.

${ }^{2}$ Enriquecimento de minerais por kg de ração: manganês $90 \mathrm{mg}$; zinco $75 \mathrm{mg}$; ferro $60 \mathrm{mg}$; cobre 9,75 mg; iodo 1,20 mg.

${ }^{3}$ Promotor de crescimento: neomicina (pré-inicial), bacitracina (inicial).

${ }^{4}$ Anticoccidiano: nicarbazina (pré-inicial), narasina (inicial).

*Valorização dos nutrientes com o uso das enzimas em estudo.

Os resultados de consumo de ração (CR), ganho de peso (GP), conversão alimentar (CA) e características de carcaça foram submetidos à análise de variância pelo pacote computacional SISVAR (Sistemas para Análises de Variância), segundo FERREIRA (2000), realizando teste de Scott Knott e contrastes ortogonais para comparação múltipla das médias. Os contrastes testados foram: 1) dietas ausentes da associação de carboidrases e fitase versus dietas com inclusão do complexo enzimático; 2) tratamento 1 versus tratamento $3 ; 3$ ) tratamento 2 versus tratamento 4. 
TABELA 2- Composição percentual e níveis nutricionais calculados das rações experimentais nas fases crescimento e final

\begin{tabular}{|c|c|c|c|c|c|c|c|c|}
\hline & \multicolumn{4}{|c|}{ Crescimento } & \multicolumn{4}{|c|}{ Final } \\
\hline Ingredientes & T1 & $\mathrm{T} 2$ & T3* & T4* & T1 & $\mathrm{T} 2$ & T3* & T4* \\
\hline Milho & 60,49 & 65,34 & 65,34 & 70,07 & 62,51 & 67,15 & 67,42 & 72,02 \\
\hline Farelo de soja, $45 \%$ & 19,34 & 20,34 & 18,68 & 19,73 & 16,98 & 14,8 & 21,31 & 19,91 \\
\hline Soja integral tostada & 7,00 & 3,00 & 7,00 & 3,00 & 8,00 & 8,00 & 1,91 & 1,00 \\
\hline Far. Carne e osso, $40 \%$ & 6,53 & 6,55 & 4,55 & 4,57 & 5,58 & 5,58 & 3,62 & 3,63 \\
\hline Gordura de aves & 4,63 & 2,96 & 2,16 & 0,56 & 4,77 & 2,48 & 3,33 & 1,20 \\
\hline Calcário & 0,09 & 0,10 & 0,32 & 0,33 & 0,32 & 0,33 & 0,55 & 0,56 \\
\hline Sal comum & 0,32 & 0,32 & 0,35 & 0,35 & 0,34 & 0,34 & 0,37 & 0,37 \\
\hline Suplemento vitamínico ${ }^{1}$ & 0,05 & 0,05 & 0,05 & 0,05 & 0,05 & 0,05 & 0,05 & 0,05 \\
\hline Suplemento mineral $^{2}$ & 0,05 & 0,05 & 0,05 & 0,05 & 0,05 & 0,05 & 0,05 & 0,05 \\
\hline Dl-metionina (99\%) & 0,246 & 0,176 & 0,23 & 0,16 & 0,207 & 0,143 & 0,191 & 0,126 \\
\hline L-lisina (78\%) & 0,274 & 0,19 & 0,279 & 0,194 & 0,236 & 0,167 & 0,229 & 0,158 \\
\hline L-treonina (99\%) & 0,092 & 0,039 & 0,083 & 0,029 & 0,065 & 0,018 & 0,052 & 0,005 \\
\hline Promotor de crescimento $^{3}$ & 0,395 & 0,395 & 0,395 & 0,395 & 0,900 & 0,900 & 0,900 & 0,900 \\
\hline Anticoccidiano $^{4}$ & 0,495 & 0,495 & 0,495 & 0,495 & - & - & - & - \\
\hline Complexo enzimático & - & - & 0,020 & 0,020 & - & - & 0,020 & 0,020 \\
\hline Fitase & - & - & 0,005 & 0,005 & - & - & 0,005 & 0,005 \\
\hline Caulin & - & - & - & - & - & - & - & - \\
\hline Total & 100,00 & 100,00 & 100,00 & 100,00 & 100,00 & 100,00 & 100,00 & 100,00 \\
\hline \multicolumn{9}{|c|}{ Composição nutricional calculada } \\
\hline $\begin{array}{l}\text { Energia metabolizável } \\
(\mathrm{kcal} / \mathrm{kg})\end{array}$ & 3250 & 3153 & 3250 & 3153 & 3290 & 3191 & 3290 & 3191 \\
\hline Proteína bruta (\%) & 19,50 & 18,72 & 19,50 & 18,72 & 18,50 & 17,76 & 18,50 & 17,76 \\
\hline Lisina digestível (\%) & 1,07 & 0,96 & 1,07 & 0,96 & 0,99 & 0,89 & 0,99 & 0,89 \\
\hline $\begin{array}{l}\text { Metionina + Cistina digestível } \\
(\%)\end{array}$ & 0,77 & 0,70 & 0,77 & 0,70 & 0,72 & 0,65 & 0,72 & 0,65 \\
\hline Treonina digestível (\%) & 0,70 & 0,63 & 0,70 & 0,63 & 0,64 & 0,58 & 0,64 & 0,58 \\
\hline Cálcio (\%) & 0,90 & 0,90 & 0,90 & 0,90 & 0,87 & 0,87 & 0,87 & 0,87 \\
\hline Fósforo disponível (\%) & 0,50 & 0,50 & 0,50 & 0,50 & 0,44 & 0,44 & 0,44 & 0,44 \\
\hline Sódio & 0,19 & 0,19 & 0,19 & 0,19 & 0,19 & 0,19 & 0,19 & 0,19 \\
\hline
\end{tabular}

${ }^{\mathrm{T}}$ Enriquecimento de vitaminas por kg de ração: selênio $0,30 \mathrm{mg}$; vitamina A $10.000 \mathrm{UI}$; vitamina D3 $2.500 \mathrm{UI}$; vitamina E $25 \mathrm{mg}$; vitamina K3 $2 \mathrm{mg}$; vitamina B1 2,50 mg; vitamina B2 6,50 mg; vitamina B6 3,50 mg; vitamina B12 18 mcg; ácido fólico 1,20 mg; ácido pantotênico $15 \mathrm{mg}$; niacina $42 \mathrm{mg}$; biotina $80 \mathrm{mcg}$; etoxiquin $166 \mathrm{mg}$.

${ }^{2}$ Enriquecimento de minerais por kg de ração: manganês $75 \mathrm{mg}$; zinco 62,50 mg; ferro $50 \mathrm{mg}$; cobre 8,125 mg; iodo $1 \mathrm{mg}$.

${ }^{3}$ Promotor de crescimento: bacitracina (somente crescimento).

${ }^{4}$ Anticoccidiano: narasina.

*Valorização dos nutrientes com o uso das enzimas em estudo.

\section{RESULTADOS E DISCUSSÃO}

Os resultados de desempenho dos frangos de corte, no período de 1 a 42 dias de idade, encontramse apresentados na Tabela 3.
Observou-se efeito significativo para consumo de ração (CR), peso médio ao abate (PM) e ganho de peso (GP) das aves. Os dados, quando submetidos ao teste de Scott-Knott, demonstraram diferença significativa entre os tratamentos. 
Ao analisar os contrastes ortogonais, verificou-se que para consumo de ração, peso médio e ganho de peso, o contraste 1 (tratamentos ausentes da associação de carboidrases e fitase versus tratamentos com inclusão do complexo enzimático) foi significativo $(p<0,05)$. Os tratamentos suplementados com as enzimas apresentaram aumento no consumo de ração de $5,18 \%$, e melhoria no ganho de peso de $4,39 \%$.

TABELA 3- Desempenho de 1 a 42 dias de idade de frangos submetidos a dois programas nutricionais suplementados ou não com associação de carboidrases e fitase

\begin{tabular}{lcccc}
\hline \multirow{2}{*}{ Tratamentos } & \multicolumn{4}{c}{ Características } \\
\cline { 2 - 5 } & $\mathrm{CR}^{1}, \mathrm{~g} / \mathrm{ave}$ & $\mathrm{PM}^{1}, \mathrm{~g} / \mathrm{ave}$ & $\mathrm{GP}^{1}, \mathrm{~g} / \mathrm{ave}$ & $\mathrm{CA}^{2}$ \\
\hline Tratamento 1 & $4033,8 \mathrm{a}$ & $2537,3 \mathrm{a}$ & $2492,9 \mathrm{a}$ & 1,619 \\
Tratamento 2 & $4115,9 \mathrm{a}$ & $2574,6 \mathrm{a}$ & $2530,2 \mathrm{a}$ & 1,627 \\
Tratamento 3 & $4274,8 \mathrm{~b}$ & $2679,9 \mathrm{~b}$ & $2635,6 \mathrm{~b}$ & 1,622 \\
Tratamento 4 & $4320,3 \mathrm{~b}$ & $2662,5 \mathrm{~b}$ & $2618,4 \mathrm{~b}$ & 1,651 \\
\hline Média & 4186,2 & 2613,6 & 2569,3 & 1,630 \\
\hline Coef. Variação, \% & 3,69 & 4,44 & 4,51 & 2,62 \\
Erro-padrão & 0,055 & 0,041 & 0,041 & 0,015 \\
Probabilidade & 0,003 & 0,058 & 0,058 & 0,451 \\
\hline & Probabilidade para os contrastes & & \\
\hline Tratamentos 1 e 2 vs Tratamentos 3 e 4 & 0,001 & 0,009 & 0,009 & $\mathrm{NS}$ \\
Tratamento 1 vs Tratamento 3 & 0,004 & 0,020 & 0,020 & $\mathrm{NS}$ \\
Tratamento 2 vs Tratamento 4 & 0,013 & $\mathrm{NS}$ & $\mathrm{NS}$ & $\mathrm{NS}$ \\
\hline
\end{tabular}

Descrição dos tratamentos: Tratamento 1: programa nutricional Cobb 500; Tratamento 2: com redução de 4\% na EM; 3\% PB e 10\% nas recomendações dos aminoácidos do T1; Tratamento 3: dieta reformulada isonutriente à T1 com $200 \mathrm{~g} / \mathrm{t}$ carboidrase $+50 \mathrm{~g} / \mathrm{t}$ fitase; Tratamento 4: dieta reformulada isonutriente à T2 com $200 \mathrm{~g} / \mathrm{t}$ carboidrase $+50 \mathrm{~g} / \mathrm{t}$ fitase.

${ }^{1}$ Médias seguidas de letras iguais, na coluna, não diferem estatisticamente pelo teste Scott-Knott, $10 \%$ de significância.

${ }^{2}(\mathrm{p}>0,05)$.

NS= Não significativo.

O principal efeito da adição de enzimas às dietas à base de milho e farelo de soja é a melhoria da digestibilidade dos nutrientes; por essa razão, o aumento no ganho de peso dos animais pode ter ocorrido pela maior disponibilidade de nutrientes, resultando em melhor aproveitamento desses no trato digestivo das aves.

A suplementação do complexo enzimático pode ter promovido melhor digestibilidade dos nutrientes presentes nas dietas, degradando os complexos de fibras solúveis, reduzindo a viscosidade da digesta através da degradação das arabinoxilanas solúveis das paredes celulares dos grãos, ocasionando melhor digestibilidade dos demais nutrientes.

SCOTT et al. (2001), ao estudarem a suplementação de enzimas em frangos de corte alimentados ad libitum ou de forma restrita, também verificaram maior consumo de ração para os tratamentos suplementados com $\beta$-glucanase e que a resposta à suplementação de enzimas está relacionada diretamente ao consumo voluntário de ração. SORBARA et al. (2009) avaliaram a inclusão de $\alpha$-amilase, $\beta$-glucanase e xilanase durante a fase crescimento de frangos de corte e concluíram que a suplementação enzimática pode melhorar a capacidade digestiva das aves por aumentar a digestão dos nutrientes, resultando em maior absorção e maior consumo de ração e, consequentemente, em maior ganho de peso. No entanto, GARCIA et al. (2000) e CONTE et al. (2002) não constataram efeito da adição de enzimas sobre o consumo alimentar em nenhuma das fases de criação.

Com relação ao ganho de peso, houve melhora no ganho de peso de frangos alimentados com enzimas, independentemente dos níveis nutricionais utilizados $(\mathrm{p}=0,058)$. Esses resultados são corroborados pelos obtidos por YU \& CHUNG (2004), que verificaram maior ganho de peso nas 
aves que receberam ração suplementada com complexo enzimático composto por amilase, $\beta$ glucanase e xilanase.

Tais resultados estão de acordo com os encontrados por CONTE et al. (2002) e COSTA et al. (2004), que verificaram que aves consumindo ração com suplementação enzimática obtiveram um maior ganho de peso do que aves alimentadas com rações sem suplementação enzimática. RAVINDRAN et al. (2000) e TEJEDOR et al. (2001) atribuíram o aumento no ganho de peso pela adição da enzima fitase ao incremento na digestibilidade ileal da proteína bruta, do cálcio e do fósforo.

No entanto, não se observaram diferenças sobre as variáveis estudadas entre o programa alimentar com redução dos nutrientes contidos nas dietas e o programa alimentar sem redução, sugerindo que o decréscimo de $4 \%$ na EMA, $3 \%$ na PB e $10 \%$ nos aminoácidos em todas as fases de criação pode ter sido pequeno, ou seja, a capacidade das enzimas exógenas pode ter sido subestimada.

Não houve efeito significativo $(\mathrm{p}>0,05)$ sobre a conversão alimentar (CA) na fase integral (142 dias) de criação, para os diferentes tratamentos. Esses resultados estão de acordo com GARCIA et al. (2000), FISCHER et al. (2002) e SOUZA et al. (2008), os quais suplementaram dietas à base de milho e farelo de soja com complexo enzimático e não encontraram diferenças na conversão alimentar.

Os resultados de avaliação da carcaça estão apresentados na Tabela 4. Não foram observadas diferenças significativas entre os tratamentos sobre nenhuma das medidas de qualidade de carcaça avaliadas $(\mathrm{p}>0,05)$.

TABELA 4- Rendimento de carcaça eviscerada (RPE), peito (RPP), coxa e sobrecoxa (RCS) e teor de gordura abdominal (GA) de frangos submetidos a dois programas nutricionais, suplementados ou não com associação de carboidrases e fitase, aos 42 dias

\begin{tabular}{lcccc}
\hline Tratamentos & $\mathrm{RPE}^{1}(\%)$ & $\mathrm{RPP}^{1}(\%)$ & $\mathrm{RCS}^{1}(\%)$ & $\mathrm{GA}^{1}(\%)$ \\
\hline Tratamento 1 & 74,15 & 31,40 & 34,15 & 3,28 \\
Tratamento 2 & 73,72 & 32,43 & 34,56 & 3,21 \\
Tratamento 3 & 74,96 & 32,46 & 33,70 & 3,29 \\
Tratamento 4 & 75,58 & 32,74 & 33,33 & 3,39 \\
\hline Média & 74,65 & 32,33 & 33,91 & 3,30 \\
\hline Coef. Variação, \% & 3,30 & 5,16 & 6,58 & 17,51
\end{tabular}

Descrição dos tratamentos: Tratamento 1: programa nutricional Cobb 500; Tratamento 2: com redução de 4\% na EM; 3\% PB e 10\% nas recomendações dos aminoácidos do T1; Tratamento 3: dieta reformulada isonutriente à $\mathrm{T} 1 \mathrm{com} 200 \mathrm{~g} / \mathrm{t}$ carboidrase $+50 \mathrm{~g} / \mathrm{t}$ fitase; Tratamento 4: dieta reformulada isonutriente à T2 com $200 \mathrm{~g} / \mathrm{t}$ carboidrase $+50 \mathrm{~g} / \mathrm{t}$ fitase.

${ }^{1}$ Valores calculados com base no peso da carcaça eviscerada s/ cabeça, pescoço, pés e vísceras comestíveis.

A suplementação do complexo enzimático na ração das aves não melhorou o rendimento de carcaça ou de corte de frangos abatidos com 42 dias de idade. $\mathrm{O}$ diferencial energético das dietas com redução de $4 \%$ de energia metabolizável aparente (EMA), independentemente do uso das enzimas, não interferiu no rendimento de carcaça, peito, coxa e sobrecoxa e gordura abdominal das aves criadas até os 42 dias de idade. Esses resultados corroboram os de ZANELLA et al. (1999) que, suplementando dietas à base de milho e de diferentes tipos de soja processada com complexo enzimático (amilase, xilanase e protease), não encontraram diferenças significativas em nenhum dos parâmetros de carcaça avaliados. TORRES et al. (2003), suplementando dietas à base de milho e farelo de soja com complexo enzimático (amilase, xilanase e protease), também verificaram que o rendimento de carcaça não foi influenciado pelas dietas suplementadas com enzimas.

\section{CONCLUSÃO}

A suplementação enzimática foi efetiva na recuperação do desempenho das aves alimentadas com rações decrescidas de $4 \%$ na energia metabolizável aparente, $3 \%$ da proteína bruta e $10 \%$ nas recomendações dos aminoácidos e não 
influenciou as características de carcaça.

\section{REFERÊNCIAS}

CARVALHO, J. C. C.; BERTECHINI, A. G.; FASSANI, E. J.; RODRIGUES, P. B.; PEREIRA, R. A. N. Desempenho e características de carcaça de frangos de corte alimentados com dietas à base de milho e farelo de soja suplementadas com complexos enzimáticos. Revista Brasileira de Zootecnia, Viçosa, v.38, n.2, p.292-298, 2009.

CHOCT, M. Enzymes for the feed industry: Past, present and future. World's Poultry Science Journal, Ithaca, v.62, n.1, p.5-16, 2006.

CONTE, A. J.; TEIXEIRA A. S.; BERTECHINI A. G.; FIALHO E. T.; MUNIZ J. A. Efeito da fitase e xilanase sobre a energia metabolizável do farelo de arroz integral em frangos de corte. Ciência e Agrotecnologia, Lavras, v.26, n.6, p.1289-1296, 2002.

COSTA, F. G. P.; CLEMENTINO, R. H.; JACOME, I. M. T. D.; NASCIMENTO, G. A. J.; PEREIRA, W. E. Utilização de um complexo multienzimático em dietas de frangos de corte. Ciência Animal Brasileira, Goiânia, v.5, n.2, p.63-71, 2004.

FERREIRA, D. F. SISVAR: pacote computacional. Manual do sistema SISVAR para análises estatísticas. Lavras: Universidade Federal de Lavras, 2000. 66 p.

FISCHER, G.; MAIER, J. C.; RUTZ, F. Desempenho de frangos de corte alimentados com dietas à base de milho e farelo de soja, com ou sem a adição de enzimas. Revista Brasileira de Zootecnia, Viçosa, v.31, n.1, p.402-410, 2002.

FRANCESCH, M.; GERAERT, P. A. Enzyme complex containing carbohydrases and phytase improve growth performance and bone mineralization of broilers fed reduced nutrient corn-soybean-based diets. Poultry Science, Champaign, v.88, n.9, p.1915-1924, 2009.

GARCIA, E. R. M.; MURAKAMI, A. E.; BRANCO, A. F. Suplementação enzimática em dietas contendo farelo de soja e soja integral extrusada e efeitos na digestibilidade dos nutrientes, fluxo ileal da digesta e performance de frangos de corte. Revista Brasileira de Zootecnia, Viçosa, v.29, n.5, p.1414-1426, 2000.

GRACIA, M.; ARANÍBAR, M. J.; LÁZARO, R.; MENDEL, P.; MATEOS, G. G. $\alpha-$ Amylase supplementation of broiler diets based on corn. Poultry Science, Champaign, v.82, n.3, p.436-442, 2003.

IRISH, G. G.; BALNAVE, D. Non-starch polysaccharides and broiler performance on diets containing soyabean meal as the sole protein concentrate. Australian Journal of Agricultural Research, Victoria, v.44, n.7, p.14831499, 1993.

ODETALLAH, N. H.; WANG, J. J.; GARLICH J. D.; SHIH, J. C. H. Versazyme supplementation of broiler diets improves market growth performance. Poultry
Science, Champaign, v.84, n.6, p.858-864, 2005.

ONDERCI, M.; SAHIN, N.; SAHIN, K.; CIKIM, G.; AYDIN, A.; OZERCAN, I.; AYDIN, S. Efficacy of supplementation of alpha-amylase-producing bacterial culture on the performance, nutrient use, and gut morphology of broiler chickens fed a corn-based diet. Poultry Science, Champaign, v.85, n.3, p.505-510, 2006.

OPALINSKI, M.; MAIORKA, A.; CUNHA, F.; ROCHA, C.; BORGES, S. A. Adição de complexo enzimático e da granulometria da soja integral desativada melhora desempenho de frangos de corte. Ciência Rural, Santa Maria, v.40, n.3, p.628-632, 2010.

RAVINDRAN, V.; CABAHUG, S.; RAVINDRAN, G.; SELLE, P. H.; BRYDEN, W. L. Response of broiler chickens to microbial phytase supplementation as influenced by dietary phytic acid and nonphytate phosphorus levels II. Effects on apparent metabolisable energy, nutrient digestibility and nutrient retention. British Poultry Science, London, v.41, n.2, p.193-200, 2000 .

ROSTAGNO, H. S.; ALBINO, L. F. T.; DONZELE, J. L.; GOMES, P. C.; OLIVEIRA, R. F.; LOPES, D. C.; FERREIRA, A. S.; BARRETO, S. L. T. Tabelas Brasileiras para Aves e Suínos. Composição de Alimentos e Exigências Nutricionais. 2.ed. Viçosa: UFV, 2005. 186. p.

SCOTT, T. A.; LESLIE, M. A.; KARIMI, A. Measurements of enzyme response with hulless barleybased diets full-fed to Leghorn and broiler chicks or restricted-fed broiler chicks. Canadian Journal of Animal Science, Ottawa, v.81, p.403-410, 2001.

SORBARA, J. O. B.; MURAKAMI, A. E.; NAKAGE, E. S.; PIRACES, F.; POTENÇA, A.; GUERRA, R. L. H. Enzymatic Programs for Broilers. Brazilian Archives of Biology and Technology, Curitiba, v.52, p.233-240, 2009.

SOUZA, R. M.; BERTECHINI A. G.; SOUSA, R. V.; RODRIGUES, P. B.; CARVALHO, J. C. C.; BRITO, J. A. G. Efeitos da suplementação enzimática e da forma física da ração sobre o desempenho e as características de carcaça de frangos de corte. Ciência e Agrotecnologia, Lavras, v.32, n.2, p.584-590, 2008.

TEJEDOR, A. T.; ALBINO, L. F. T.; ROSTAGNO, H. S.; LIMA, C. A. R.; VIEITES, F. R. Efeito da adição de enzimas em dietas de frangos de corte à base de milho e farelo de soja sobre a digestibilidade ileal de nutrientes. Revista Brasileira de Zootecnia, Viçosa, v.30, n.3, p.809-816, 2001.

THORPE, J.; BEAL, J. D. Vegetable protein meals and the effects of enzymes. In: BEDFORD, M. R.; PARTRIDGE, G. G. Enzymes in farm nutrition. Londres: Cab International, 2001. p. 125-143.

TORRES, D. M.; TEIXEIRA, A. S.; RODRIGUES, P. B.; BERTECHINI, A. G.; FREITAS, R. T. F.; SANTOS, E. C. Eficiência das enzimas amilase, protease e xilanase sobre o desempenho de frangos de corte. Ciência e 
Agrotecnologia, Lavras, v.27, n.6, p.1401-1408, 2003.

YU, Bi.; CHUNG, T. K. Effects of multiple-enzyme mixtures on growth performance of broilers fed cornsoybean meal diets. Journal of Applied Poultry Research, Athens, v.13, n.2, p.178-182, 2004.
ZANELLA, I.; SAKOMURA, N. K.; SILVERSIDES, F. G.; FIQUEIRDO, A.; PACK, M. Effect of enzyme supplementation of broiler diets based on corn and soybeans. Poultry Science, Champaign, v.78, n.4, p.561$568,1999$.

Protocolado em: 25 jan. 2010. Aceito em 08 fev. 2012 